\title{
Societal Implications of the Uniform Proxemic Distance on the Internet, the Example of the Pseudonyms
}

\section{Martin $\mathbf{M}^{*}$}

University of Reunion Island, France

\begin{abstract}
In this present article, it will be discussed about the concept of proxemic distance and what it covers. This will also evoke the pseudonym or a "pleasure made a name", but the pseudonym, considered in a quite specific social dimension: Internet.
\end{abstract}

\section{Keywords: Proxemic distances; Internet; Pseudonyms}

\section{Introduction}

The Internet media which is in constant expansion is put, little by little, in competition with traditional communication objects such as television and radio. Its presence is more and more felt within the French society. INSEE [1] informs us of this social and economic change with the following (Figure 1).

In its September 2006 bulletin 1101, this last organisation states that: "The share of communication and information technology products (TIC) in the household budget went from $1.3 \%$ to $4.2 \%$ between 1960 and 2005. This, almost uninterrupted, rise does not have an equivalent amongst the other stations of significant sizes."

The Internet covers a great number of authorities, which go from the on-line publications to conversational exchanges between Net surfers, all the while passing by sites dedicated to on-line shopping. However, its characteristic lies on one part in using a uniform proxemic distance and, on another part, in taking of a pseudonym.

\section{Proxemic Distance}

The anthropologist Edward T Hall, originator of the concept of proxemic distance, says that it articulates around two factors. The first one is relative to the territory as a place of communication exchange, because "the man also observes uniform distances in relation to which he maintains with the others". The second factor corresponds to the division into distance observed between two subjects put in the situation of communication. These distances are shown in Table 1.

According to this author, whatever the sociocultural environment, "personal and social distances always exist" Indeed, human patterns are similar to animal patterns as for the concept of the distances observed by each partner at the time of interaction. However, the constancy of the distance varies according to the type of culture and the nature of the interaction. These variables correspond to that Hall calls "personal space" and "social space". In addition, the distance included between the personal distance and the social distance, called "critical distance", is subject to variations from a culture to another [1-3]. It is on this territory that the misunderstandings, the incomprehension and the conflicts take place. However, the typology of the proxemic distances, as presented and described by Hall, does not be longer accepted on Cyberspace because the distance initialised on this level is of the type

\begin{tabular}{|c|c|c|c|}
\hline \multicolumn{2}{|c|}{ Private space (personal distance) } & \multicolumn{2}{c|}{ Social space } \\
\hline $\begin{array}{c}\text { From contact with } \\
\sim 0,45 \mathrm{~m}\end{array}$ & $\begin{array}{c}\text { From } 0,45 \mathrm{~m} \text { to } \\
1,25 \mathrm{~m}\end{array}$ & $\begin{array}{c}\text { From } 1,25 \mathrm{~m} \text { to } \\
3,60 \mathrm{~m}\end{array}$ & $\begin{array}{c}\text { From } 3,60 \mathrm{~m} \text { and } \\
\text { further }\end{array}$ \\
\hline
\end{tabular}

"private distance". The latter corresponds to the symbolic distance which connects the Net surfer to his peers through a uniform proxemic distance rising from the configuration of the ensemble user/computer unit. The media Internet in which a physical system made up of a whole of interrelated computers, of individuals who ensure it the operation and of a space of numerical data, differ from the civil society because all the services suggested from the Internet are accessible only by the use of artifacts [4-8]. The consultation of Web sites while passing by the plays on the line, the electronic exchanges of messages, the deposit of comments on the forums of discussion and finally the interactive conversations pass through information processing systems. This technology makes it possible to users of the whole world to be able to communicate between them what, as regards feasibility, would be impossible with traditional means. The individuals communicate "blindly" although this other, located at the antipodes, seems near, with a computer mouse, could we say. Indeed, the perception whose speaker gets from his interlocutor is the text which is shown on the screen and an identity declined through a pseudonym [9-12]. But can one speak about social proxemic distance whereas the interlocutors are located geographically at $6000 \mathrm{~km}$ each other? Such a concept would touch with the field of the absurdity. However, the communication is realised; the speakers can discuss in real time via the screen and the keyboard. Factors emphasise the characteristic of these media as the absence of kinaesthetic demonstrations, as the interactions of communication of the symmetrical type (peer to peer) which are carried out in absentia in which each one is required to the same rule and finally as the dialogue which begins on the basis of a soliloquy [13-25].

These themes were developed from the research I have done in this particular field. Although presenting himself under a pseudonym, the Net surfer gives some signs of his private sphere. He uses markers of courtesy taken in a familiar register of language with, in particular, the use of the generalised "tu", in the French language, as well as interactions of communication of type the "peer to peer", which has as

*Corresponding author: Martin M, Associate Researcher, Oracle Laboratory, University of Reunion Island, France, Tel: +262 2629380 80, E-mail: marcienne.martin@hotmail.com

Received September 18, 2017; Accepted September 25, 2017; Published October 04, 2017

Citation: Martin M (2017) Societal Implications of the Uniform Proxemic Distance on the Internet, the Example of the Pseudonyms. J Ment Disord Treat 3: 146. doi:10.4172/2471-271X.1000146

Copyright: (c) 2017 Martin M. This is an open-access article distributed under the terms of the Creative Commons Attribution License, which permits unrestricted use, distribution, and reproduction in any medium, provided the original author and source are credited. 


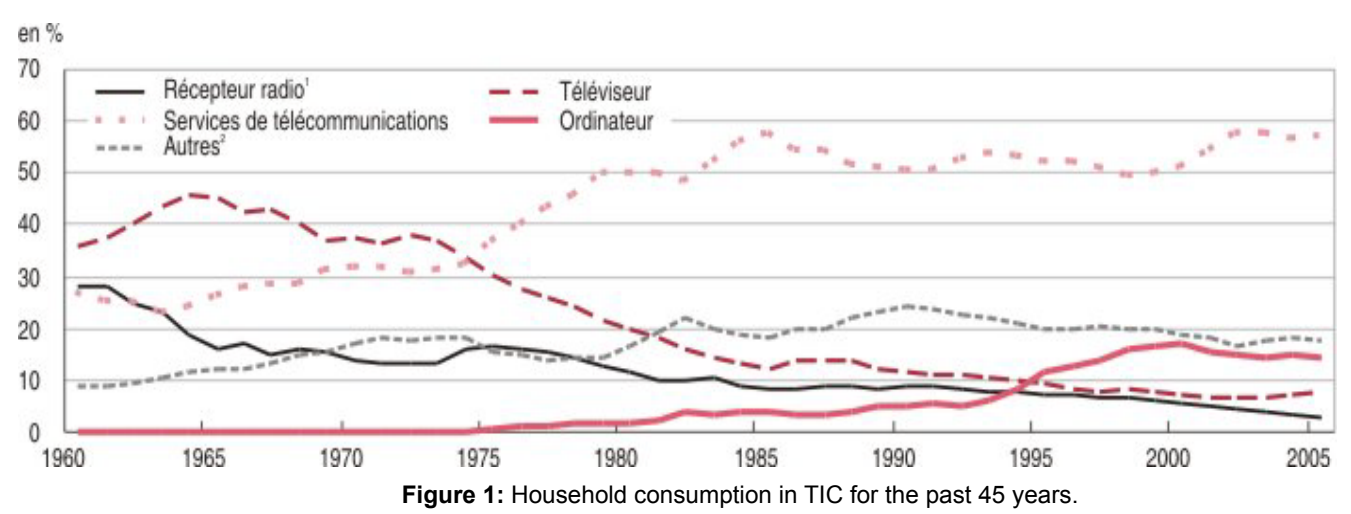

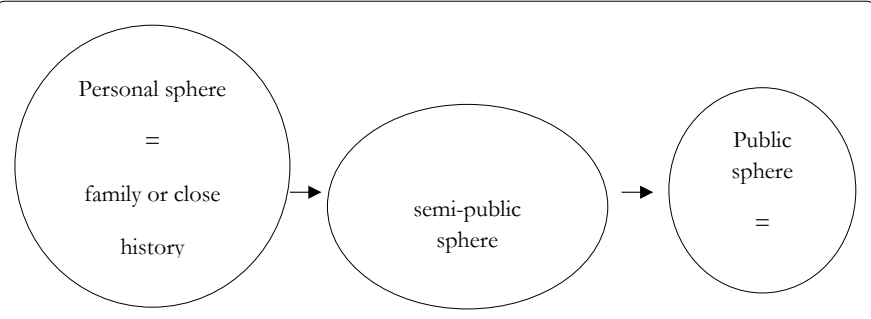

Figure 2: Representation of the onomastic variation.

a consequence the levelling of the hierarchy. To these phenomena are added to the transgression of the rule (downloading of musical, literary or filmic works considered as an exchange and not as a robbery) [1216]. This ensemble of practices supposes a correlation to the private sphere of the subject and not to the social sphere from where the evacuation of the following markers: use of formal courtesy, hierarchy, differentiation of the statutes and roles, unambiguous rule, etc. These social practices would be a direct consequence of the proxemic distance installation made up between the Net surfer and its screen, this last having a particular value in a symbolic system because it means the other, so much in its quality of interlocutors than in his common membership.

This phenomenon was corroborated by an investigation put on the line and in which it was requested from the Net surfer to define his pseudonym in categories between personal life and social objects. The following figure shows that the majority of the Net surfers chose the items in relation to their personal life. In order to clarify my subject, I specify that the item "social object" corresponds to a material or immaterial built reality and in connection with the human society and their members through their culture and their laws such as for example the pseudonyms Bob MORANE, lucifer, Newverlaine; personality with: "what differentiates a person of all the others" [26-28] as softness or demoniak; personal history with the biography of the subject (Figures 2 and 3) [29-32].

Within the framework of this investigation, some Net surfers mention that they use anthroponyms already used in the family circle or in close relations, which corresponds to the item "personal history". Some users want their pseudonym to be recognised by their correspondent. The following examples, extracted from the corpus of the answers to the investigation put on the line, are the perfect illustration.

These three classes set of themes could be represented on an axis: personal sphere $v s$ public sphere, while passing by a sphere which

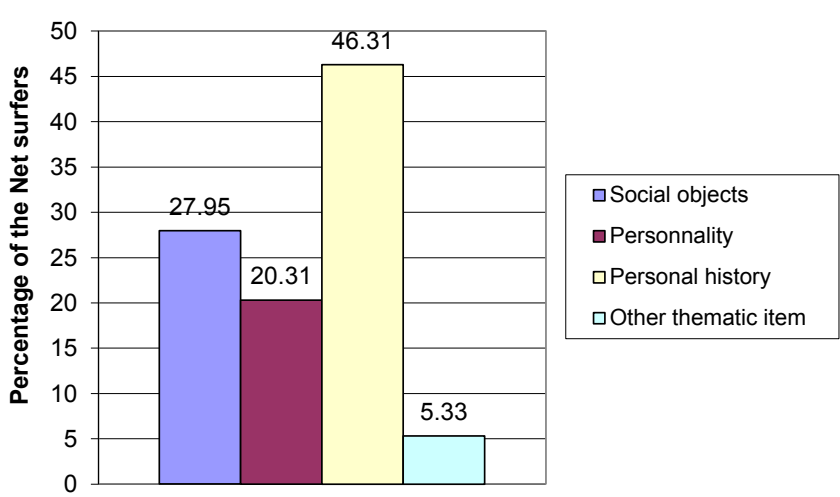

Figure 3: Onomastic choice of the Net surfer.

would correspond to a transition and which one could name "semipublic sphere" (Figure 3).

Indeed, if in the civil society, it is the law making (the law) and the first name that give its existence to the subject through the proper name (first name and surname), in this digital society that is the Internet, the current rule consists of taking a false name (pseudonym) which will be the user's virtual identity in this media where it is impossible to circumvent the inscription within the different forum or chat rooms. This autonomous makes it possible for the user to hide behind a fictitious identity and to occupy a space located outside of all social rules. For the Net surfer, this name will define him as a user in Internet Cyberspace in such or such community. However, all these identities coexist with that of the real name (first name and surname), the legitimate name circumscribed by the law. In this virtual society made of individuals from different parts of the world and different cultures, it is the "I" who names himself in order to be recognised and accepted by the other, whereas in the traditional society type, it is the other one who names the "I". The group of Internet users has a project registered in. The structure of the group is abstract: it is not always the same users who meet in the chat rooms or on the forums. Almost $50 \%$ of the consulted Net surfers say to have built their pseudonym on the territory pertaining to the private sphere (family, friends, etc.). Additional examples of pseudonyms will be presented in the following paragraphs.

Do Nintendo players unknowingly reveal some clues on their taste for games through their names? We can see it on this print screen with roots "niten" such as "netnintenfan" and "nitendoien" which reveals the membership while referring to Nintendo and the suffixes "fan" and 


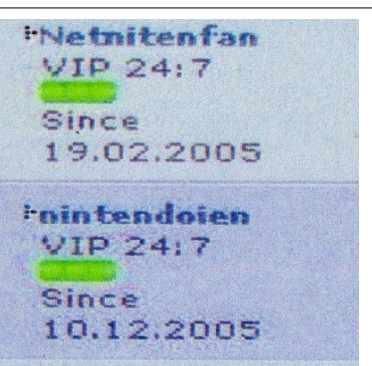

Figure 4: An example of pseudonyms.

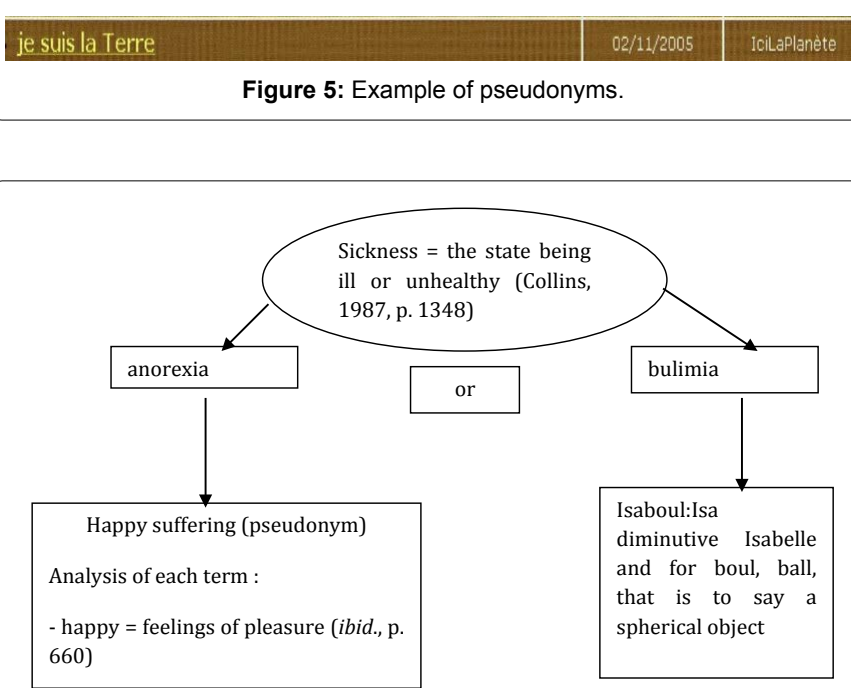

Figure 6: Semantic fields and pseudonyms.

"doien" which locates the Net surfer through markers in an emotional space (Figure 4) [33-38].

In this other forum which has a subject that concerns each one of us: global warming; the screen print shows an implicit and a reinforcement of the content of the subjects suggested by the various speakers through their pseudonym. Thus, the Net surfer called: Return to nature proposes a discussion on "leaving the cities" while the Net surfer called: to see clearly entitles his proposal for a discussion: "Global warning: is there another cause?". This semantic redundancy reaches its full realisation in this autonomous: Here is the Earth. We can note the installation of dialogism in which the pseudonym takes on a third voice: that of the planet. The semantic redundancy is in the body of the message: I am the Earth. The anthropomorphic values given to this object are communicated by the capital letters introducing each part of the idiom with regards to the false name and the lexical item "Earth" for the message title. I would like to add that out of the 16 speakers, 5 have a pseudonym which refers to the membership, i.e. with the object of this forum (Figure 5) [39-43].

I also chose a forum that touches each one of us in a more intimate sphere, i.e. health. It is evoked in diseases such as anorexia and bulimia. The Net surfers having integrated this forum chose the autonomous ones who "tell", in a synthetic form, the problems, that they encounter. The lexicographical analysis of each pseudonym will tell us about their significance. They are correlated with the semantic fields concerned (Figure 6).

\section{Conclusion}

To conclude, I, certainly, have evoked the process of structuring a group with the inscription of almost its members around their private sphere, but this modus operandi cannot explain the creation of names related to semantic fields correlated with the emotional sphere. The uniform proxemic distance from type "private distance" generates social practices in relation to the personal sphere of the individual and which seem to apply stricto sensu to the Cyberspace. These new social practices transform the interpersonal and intergroup links. This predetermination of a uniform proxemic system, applied to the group of the Net surfers and correlated to the phylogenetic structure of the human subject, would generate an ensemble of similar social practices from one individual to another, that the subject "navigates" on the Internet within a formal or informal group. It seems that this type of media generates particular links which abolish the various roles whose various social actors are invested. In this case, it also seems that a work of catharsis is carried out through the nomination. Bourdieu specifies that "the act of social magic consisting of trying to produce the existence of the named thing can succeed if those who achieve are able to get it recognised with its word the capacity which it assumes". But to name itself isn't to pose an act of the preformative type? Doesn't the share of subjectivity, which is in each Net surfer, emerge in pseudonyms such as "happy suffering" or "Here is the Earth", which would be a way to conjure fate by lexical homonymy and magic of words? Because "to say", isn't it, sometimes, to "want to be"? In addition, the uniform proxemic distance system on the Internet, won't it be at the origin of innovative social paradigms?

\section{References}

1. Aebischer V, Oberle D (1990) The group in social psychology. Paris: Dunod

2. Austin JL (1962) When to say is to do. Paris: Seuil.

3. Benabou C, Abravanel $\mathrm{H}$ (1986) The behavior of individuals and groups in the organization. Montreal: Gaëtan Morin.

4. Bera M, Mechoulan E (1999) The Internet machine. Paris: Odile Jacob.

5. Bourdieu P (2001) Language and symbolic power. Paris: Fayard.

6. Breton P, Proulx S (1994) The explosion of communication: the birth of a new ideology, Louiseville: Boréal.

7. Bretton P (2000) The cult of the Internet. Paris: The Discovery.

8. English language dictionary (1987) London: Collins Cobuild.

9. Eco U (1980) The sign. Brussels: Labor. 1988.

10. Eco U (1988) Semiotics and the philosophy of language. Paris: PUF.

11. Flichy P (1997) A history of modern communication. Paris: The Discovery

12. Fortier F (1963) Citizens under surveillance: the hidden face of the Internet Montreal: Ecosocities.

13. Ganascia JG (1998) Dictionary of Computer Science and Information Sciences Paris: Flammarion

14. Ghiglione R (1986) The communicating man. Paris: Armand Colin.

15. Goose A, Grevisse M (1993) Good usage: French grammar. Paris: Duculot.

16. Grevisse M (1969) Precis of French grammar. Paris: Duculot.

17. Hagege C (1985) The man of words. Paris: Fayard.

18. Hall TE (1966) The hidden dimension. Paris: Seuil.

19. Hogue JP, Lévesque D, Morin ME (1988) Group, power and communication Montreal: Presses of the University of Quebec

20. Dictionary of computer science: standardized vocabulary (1997) Paris: ISO/ AFNOR.

21. Laugaa M (1986) The thought of the pseudonym. Paris: PUF 
Citation: Martin M (2017) Societal Implications of the Uniform Proxemic Distance on the Internet, the Example of the Pseudonyms. J Ment Disord Treat 3: 146. doi:10.4172/2471-271X.1000146

Page 4 of 4

22. Lecler J (1986) Language and society. Laval: Mondia.

23. Larousse LP (1998) Dictionary of French Canada: Les Éditions Françaises Inc.

24. Robert LP (1967) Dictionary of the French language. Paris: The Robert.

25. Robert LP (1967) Alphabetical and analogic dictionary of the French language Paris: Dictionaries Le Robert.

26. Robert LP (1995) ALL-Dictionary of the French Language Paris: Dictionaries Le Robert.

27. Straus LC (1962) Wild thought. Paris: Plon.

28. Malmberg B (1979) Language: the sign of the human. Paris: Picard.

29. Martin M (2005) The identity constructions of the subject through the implementation of pseudonyms and the emergence of a new language code via the internet tool.

30. Martin M (2006) The pseudonym on the Internet - A nomination located the crossroads of anonymity and private sphere. Paris: Editions L'Harmattan.

31. Martin M (2007) Language on the Internet - Old Knowledge scanned. Paris: Editions L'Harmattan.
32. Mintzberg H (1982) Structure and dynamics of organizations. Paris: Editions d'Organization.

33. Proulx S (2004) The Internet revolution in question. Montreal: Quebec America

34. Rey A (2000) Historical Dictionary of the French Language. Paris: The Robert.

35. Vaillant $P$ (1999) Semiotics of icon languages. Paris: Honoré Champion.

36. Watzlawick P, Beavin HJ, Jackson D (1972) A logic of the communication Paris: Seuil.

37. Wolton D (2000) Internet and after? Paris: Flammarion.

38. Arthaut R (2006) Household consumption in ICT over 45 years. Paris: Insee Première.

39. http://atilf.atilf.fr/tlf.htm

40. http://forum.doctissimo.fr

41. http://community.nintendo-europe.com/forum

42. https://www.insee.fr/en/accueilhttp://www.insee.fr/en/home/home_page.asp 43. https://servicewebmaster.jimdo.com/allopass/http://www.servicewebmaste 